\title{
O COMITÊ DE BACIA \\ HIDROGRÁFICA COMO FOCO DE \\ ESTUDO EM DISSERTAÇÕES E TESES
}

\author{
Mario Marcos Lopes ${ }^{1}$ \\ Maria Lucia Ribeiro ${ }^{2}$ \\ Denilson Teixeira ${ }^{3}$
}

\section{RESUMO}

A presente pesquisa tem como objetivo inventariar os temas e autores voltados ao estudo dos Comitês de Bacia Hidrográfica e lacunas existentes neste campo de pesquisa. A organização da base de dados para as análises se deu por meio da identificação e seleção dos trabalhos de 1987 até 2012, a partir do banco de teses da Coordenação de Aperfeiçoamento de Pessoal de Nível Superior (CAPES). Para a busca utilizaram-se como palavras-chave: Comitê de Bacia Hidrográfica. O inventário é formado por 81 trabalhos, entre dissertações e teses e está organizado e analisado sob os seguintes aspectos: caracterização geral, análise disciplinar, temática e autores. Os dados revelam que o interesse pela pesquisa vem crescendo nas Instituições de Ensino Superior pelo Brasil e que diversas áreas do conhecimento vêm pesquisando sobre os Comitês, tornando-a, assim, uma área particular de estudo.

Palavras-chave: Comitê de bacia hidrográfica. Banco de teses CAPES.Inventário.

${ }^{1}$ Centro Universitário Barão de Mauá; Faculdade de Educação São Luís de Jaboticabal.

${ }^{2}$ Programa de Desenvolvimento Territorial e Meio Ambiente - UNIARA.

${ }^{3}$ Programa de Pós-Graduação em Ciências Ambientais - UFG (CIAMB). 


\title{
THE COMMITTEE OF BASIN AS A FOCUS OF STUDY IN DISSERTATIONS AND THESIS
}

\begin{abstract}
This research aims at listing the themes and authors focusing on the study of Watershed Committees and the existing gaps in this research field. The organization of the database for the analyses was carried out by identifying and selecting the works produced from 1987 to 2012, in the databank of theses of Coordenação de Aperfeiçoamento de Pessoal de Nível Superior (CAPES). The keyword used for the search was: Watershed Committee. The inventory consists of 81 works, including dissertations and theses, and is organized and analyzed on the following aspects: general characterization, disciplinary analysis, themes and authors. The data show that the interest in research has increased in higher education institutions in Brazil and several areas of knowledge have been researching on the Committees, becoming a particular area of study
\end{abstract}

Keywords: Watershed committee. CAPES Theses Database. Inventory.

\section{INTRODUÇÃO}

Nos últimos vinte e cinco anos tem se produzido um conjunto significativo de pesquisas conhecidas pela expressão "estado da arte" ou "estado do conhecimento" nas mais diversas áreas de pesquisa (ROMANOWSKI \& ENS, 2006). Essencialmente de caráter bibliográfico, elas trazem em comum o desafio de mapear e de discutir determinada produção acadêmica em diferentes campos do conhecimento, tentando responder que aspectos e dimensões vêm sendo destacados e privilegiados em diferentes épocas e lugares, de que formas e em que condições têm sido elaboradas as dissertações de mestrado, teses de doutorado, publicações em periódicos e comunicações em anais de congressos e de seminários. Também são reconhecidas por realizarem uma metodologia de caráter inventariante e descritivo da produção acadêmica e científica sobre o tema que busca investigar.

Soares (1987, p.3) justifica a relevância de trabalhos nessa natureza:

\begin{abstract}
Essa compreensão do estado de conhecimento sobre um tema, em determinado momento, é necessária no processo de evolução da ciência, afim de que se ordene periodicamente o conjunto de informações e resultados já obtidos, ordenação que permita indicação das possibilidades de integração de diferentes perspectivas, aparentemente autônomas, a identificação de duplicações ou contradições, e a determinação de lacunas e vieses.
\end{abstract}

Diante do exposto, a presente pesquisa teve como objetivo identificar e caracterizar os trabalhos de Mestrado e Doutorado defendidos no Brasil até 2012, nos quais o Comitê de Bacia Hidrográfica foi o objeto de estudo seja de forma direta por meio da análise do Comitê ou indireta, fornecendo subsídios para atuação dos mesmos e, a partir dessa base de dados, analisar a produção dos principais autores, buscando, também, identificar possíveis lacunas existentes nesse campo de pesquisa.

As bacias hidrográficas, tornaram-se, à curto prazo, instrumentos complementares para as unidades político-administrativas para a efetivação do planejamento e da gestão, passando a representar unidades territoriais sujeitas a um ordenamento espacial próprio, principalmente quando os Comitês de Bacias 
Hidrográficas assumiram um desempenho que deveria ter por responsabilidade a atuação mais direta do Estado.

Os comitês de bacias hidrográficas, instituídos pela Lei Federal n 9.433, de 08 de janeiro de 1997 , como parte integrante do Sistema de Gerenciamento de Recursos Hídricos, configuram-se como instituições relativamente recentes no Brasil, criadas nas duas últimas décadas do século XX. A história do seu surgimento e as demandas sociais que os envolvem geram uma expectativa em que as práticas de organização espacial sejam realizadas de uma forma diversa da que tradicionalmente ocorria como tentativas de planejamento e gestão do território. Neste sentido, essas instâncias se tornam objetivos riquíssimos para pesquisa e discussão por se tratar de um objeto complexo e ao mesmo tempo intrigante.

Paralelamente, Fracalanza \& Lima (2006) ao desenvolver pesquisa semelhante envolvendo educação ambiental (EA) no Brasil comentam que devido à abrangência da temática e ao fato da produção acadêmica ser realizada em distintos programas de pós-graduação, torna-se difícil a recuperação, tanto das variadas informações sobre EA assentadas pelas pesquisas, quanto das controvérsias existentes no campo, bem como das reais configurações dos recortes teóricos, dos objetos, objetivos e procedimentos de investigação que constituem o âmago dos trabalhos. Essa constatação pode ser estendida ao tema Comitês de Bacia Hidrográfica, por se tratar de uma área em expansão, configurando-se ainda os principais grupos de pesquisa.

Destaca-se ainda que os comitês de bacias hidrográficas são os espaços adequados para o debate democrático sobre o uso das águas e também para congregar diversos conhecimentos técnicos e os obtidos através da realidade vivida, visando um gerenciamento adequado das águas, que possibilite o uso por todos, sem que haja prejudicados. Por isso, estudar como o meio cientifico está abordando a temática é extremamente importante.

Por fim, o presente artigo prima pela originalidade do tema, ao levantar a produção cientifica no Brasil sobre os Comitês de Bacia Hidrográfica, foco de estudo, que se encontra em ascendência por se tratar de objetivo rico para discussão.

\section{Comitê de Bacia Hidrográfica: objetivos, organização e aspectos gerais}

A Política Nacional de Recursos Hídricos, instituída pela Lei n. ${ }^{\circ}$ 9.433, de 8 de janeiro de 1997, incorpora princípios e normas para a Gestão de Recursos Hídricos, adotando a definição de bacias hidrográficas como unidades de estudo e gestão (TEODORO et.al., 2007).

Nessa nova concepção de Gestão de Recursos Hídricos, estabelecida pela referida lei, cabe aos comitês de bacia, muito além da posição de usuários/consumidores, intervirem na definição da política pública de gestão de recursos hídricos, a qual, inevitavelmente, possui uma clara interface com o modelo de desenvolvimento adotado em uma região (GARJULLI, 2003).

Esse modelo adotado no país é inspirado no modelo francês, que é por sua vez adaptado do sistema alemão. Teoricamente, o comitê de bacia paulista funciona como um verdadeiro "parlamento das águas", a partir de princípios norteadores que preconizam a gestão compartilhada, tendo como base de sustentação a descentralização, a integração e a participação no destino dos recursos hídricos de cada região de bacia.

Os Comitês de Bacias Hidrográficas (CBHs) são órgãos colegiados descentralizados, com atribuições normativas, deliberativas e consultivas, constituídos por representantes de três segmentos com paridade de voto: estado, municípios e entidades da sociedade civil sediadas na bacia (MASCARENHAS, 2006).

Diversas funções competem aos CBHs, segundo a Política de Recursos Hídricos, entre elas: aprovar a proposta da bacia hidrográfica, para integrar o Plano Estadual de Recursos Hídricos e suas atualizações; aprovar a proposta de programas anuais e plurianuais de aplicação de recursos financeiros em serviços e obras de interesse para o gerenciamento dos recursos hídricos; aprovar a proposta do plano de utilização, 
conservação, proteção e recuperação dos recursos hídricos da bacia hidrográfica; promover entendimentos, cooperação e eventual conciliação entre os usuários dos recursos hídricos; promover estudos, divulgação e debates, dos programas prioritários de serviços e obras a serem realizados no interesse da coletividade; apreciar o relatório sobre "A Situação dos Recursos Hídricos da Bacia Hidrográfica".

Observa-se que diversos estados brasileiros já reorganizaram sua legislação, conforme os princípios preconizados pela Política Nacional de Recursos Hídricos, conforme apontam Lopes \& Teixeira (2012) em seu trabalho "A trajetória da gestão dos recursos hídricos no Brasil: panorama geral dos estados brasileiros". Neste estudo, os autores apresentam a trajetória e a evolução dos estados na Gestão de Recursos Hídricos, além de traçar um levantamento da instalação e funcionamento dos Comitês no país.

Entretanto, apesar da grande inovação trazida por esse novo modo de gestão, a instalação de um comitê não significa que ele esteja atuando com eficiência (ABERS \& JORGE, 2005). O efetivo funcionamento dos Comitês de Bacias Hidrográficas implica modificações profundas no âmbito cultural e administrativo do Estado brasileiro. A criação dos comitês marca o início da ruptura com políticas desenvolvimentistas e ambientais pontuais e são peças fundamentais para a garantia do sucesso da gestão sustentável dos recursos hídricos no Brasil (KETTELHUT et.al., 1998).

Por isso, as temáticas relacionadas aos Comitês de Bacia Hidrográfica mostram-se como um terreno extremamente fértil para o desenvolvimento de estudos, pesquisa e atuação e seus resultados devem estender-se a outras instâncias e instituições de ensino e extensão.

\section{PROCEDIMENTOS METODOLÓGICOS}

O banco de dados utilizado para a pesquisa foi o Portal de Teses e Dissertações da Coordenadoria de Aperfeiçoamento de Ensino Superior - Portal CAPES, bem como da divulgação das publicações científicas.

De acordo com Soares (2004, p. 2), o Portal da Capes possui importância estratégica relativamente ao desenvolvimento científico do país, uma vez que constitui "o teto para o embasamento empírico, teórico e comparativo de muitas pesquisas".

Inicialmente o universo de estudo desta pesquisa foi composto por 189 trabalhos científicos (Dissertações e Teses) defendidos desde 1987, e recuperados no Banco da CAPES, até 2012, entretanto, após análise inicial verificou-se que alguns dos trabalhos tinham o $\mathrm{CBH}$ como foco indireto de estudo, ou seja, fornecia apenas subsídios para os mesmos. Diante dessa constatação optou-se por analisar apenas os 81 trabalhos cujo objetivo principal era os Comitês, estabelecendo a partir desse ponto as seguintes etapas, baseada na proposta de Vasco \& Zakrzevski (2010):

$1^{\text {a }}$ Etapa - mapeamento da produção acadêmica sobre Comitê de Bacia Hidrográfica: identificação das dissertações e teses que possuem a temática seja direta ou indiretamente como objeto de pesquisa, dos PPG Stricto Sensu brasileiros que pesquisam sobre esse tema.

$2^{\mathrm{a}}$ Etapa - elaboração de um Banco de Dados: leitura sistemática dos resumos, identificando os trabalhos que, indicavam uma inserção no campo de pesquisa e elaboração de um Banco de Dados para sistematizar e possibilitar um olhar sobre o que se pesquisa na área, identificando elementos centrais para análise (nome do autor, título, ano de defesa, orientador, instituição, programa, tema de pesquisa, visão geral dos instrumentos de pesquisa, sujeitos envolvidos e local de realização do estudo).

$3^{\text {a }}$ Etapa - análise de conteúdo dos resultados: realizada a partir do Banco de Dados, possibilitou caracterizar, quantificar, identificar possíveis tendências consolidadas a partir das pesquisas sobre os Comitês de Bacia Hidrográfica, produzidas junto aos PPG Stricto Sensu.

Em alguns casos, para análise mais detalhada dos temas, autores e procedimentos metodológicos, fez-se necessária a busca dos trabalhos na íntegra. 


\section{RESULTADOS E DISCUSSÕES}

A pós-graduação deve ser a base para visão integrada e integradora promovendo novas abordagens no processo de gestão por meio dos Comitês de Bacia Hidrográfica, com reflexos na economia, no uso consciente dos recursos naturais, no desenvolvimento tecnológico da gestão, entre outros (TUNDISI, 2010).

Nota-se que a produção científica acerca do tema em discussão iniciou-se no ano de 1996, com uma dissertação de mestrado da autora Maria Teresa Mariano, defendida na Universidade de São Paulo(USP) - Campus São Carlos (USP) no programa de pós-graduação em Ciências da Engenharia Ambiental, observando que o referido trabalho analisa como ocorre a participação da sociedade civil no Sistema de Gestão dos Recursos Hídricos do Estado de São Paulo, considerado o estado pioneiro na formulação de uma política voltada à temática (LEI no 7.663, de 30 de dezembro de 1991). Analisou-se o papel da sociedade organizada nos canais formais de participação, tais como: CONSEMA e Comitê de Bacia Hidrográfica.

Observou-se que praticamente $56 \%$ da produção acadêmica se concentram nos últimos cinco anos (2008 a 2012), tendo seu auge no ano em 2011, com 14 trabalhos defendidos, representando $17 \%$ do total. A evolução da produção das pesquisas no período estudado está apresentada na Figura 1.

Figura 1 - Evolução da produção das dissertações e teses no período de 1996 a 2012

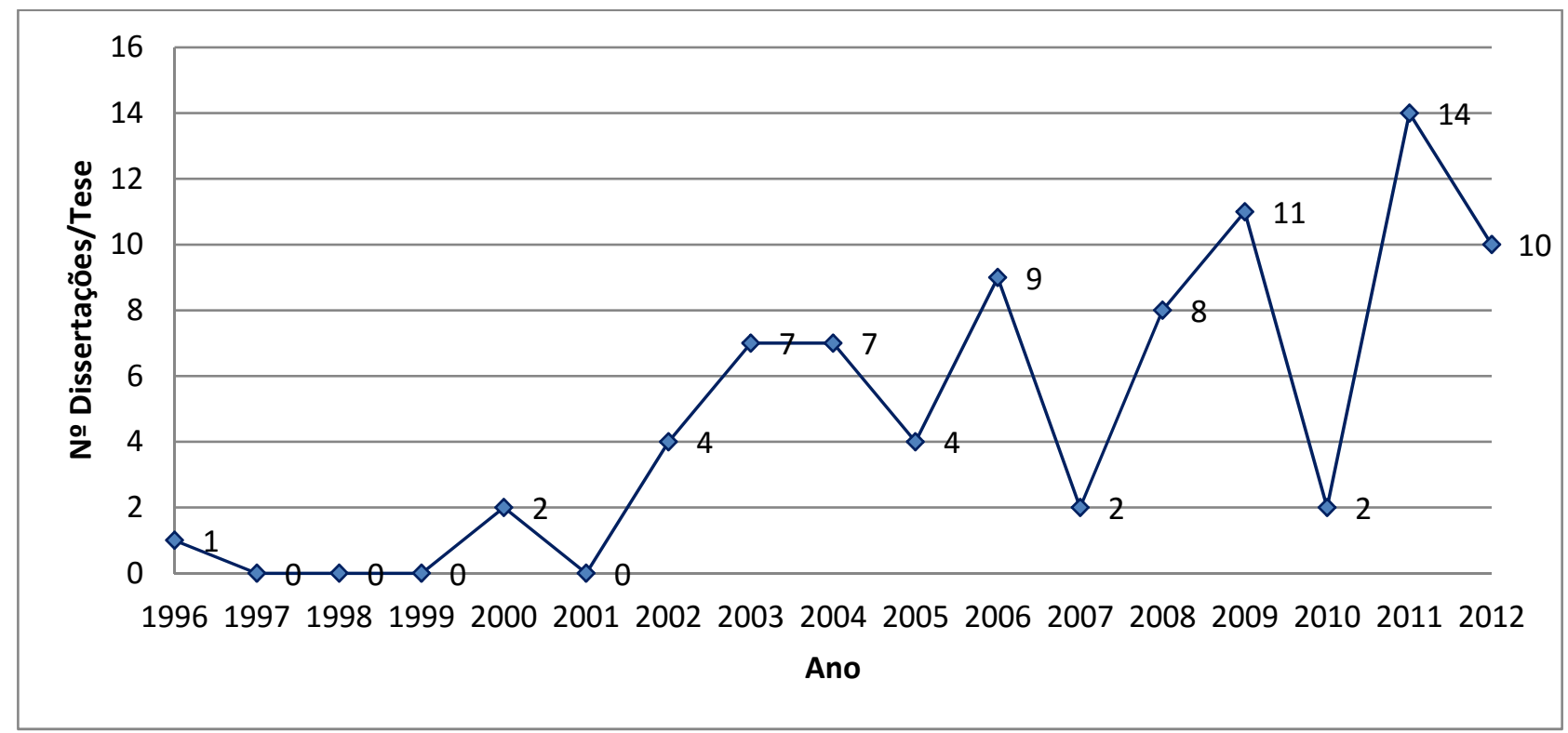

Fonte: Dados compilados pelo autor a partir de informações do Banco de Dados Capes (1987 a 2012)

Os comitês de bacias hidrográficas são um tipo de organização inteiramente nova na administração dos bens públicos no Brasil, por isso, os estudos voltados a avaliações das ações destes organismos são extremamente recentes. Destinados a agir como "parlamento das águas da bacia”, são o fórum de decisão no âmbito de cada bacia hidrográfica, compostos por representantes dos usuários, das prefeituras, da sociedade civil organizada e dos demais níveis de governo.

É importante destacar uma variação de trabalhos ao longo do período avaliado, necessitando um 
estudo mais aprofundado, a fim de determinar o porquê de tais variações. No tocante a caracterização das Instituições de Ensino Superior (IES) na qual os trabalhos foram defendidos, apontou-se que são, em sua maioria, instituições públicas (84\%), e 16\% em privadas, responsáveis por 16 dissertações, confirmando a tendência geral e atual de que a maior parte da produção científica brasileira se situa na universidade pública.

$\mathrm{Na}$ análise do número de trabalhos por IES, destacou-se a Universidade de São Paulo (USP), onde $17 \%$ dos trabalhos (dissertações e teses) saíram dos seus programas de pós-graduação. O número de teses por instituição está representado na Figura 2.

Figura 2 - Gráfico crescente evidenciando a quantidade de dissertações/teses defendidas nas IES entre 1996 e 2012

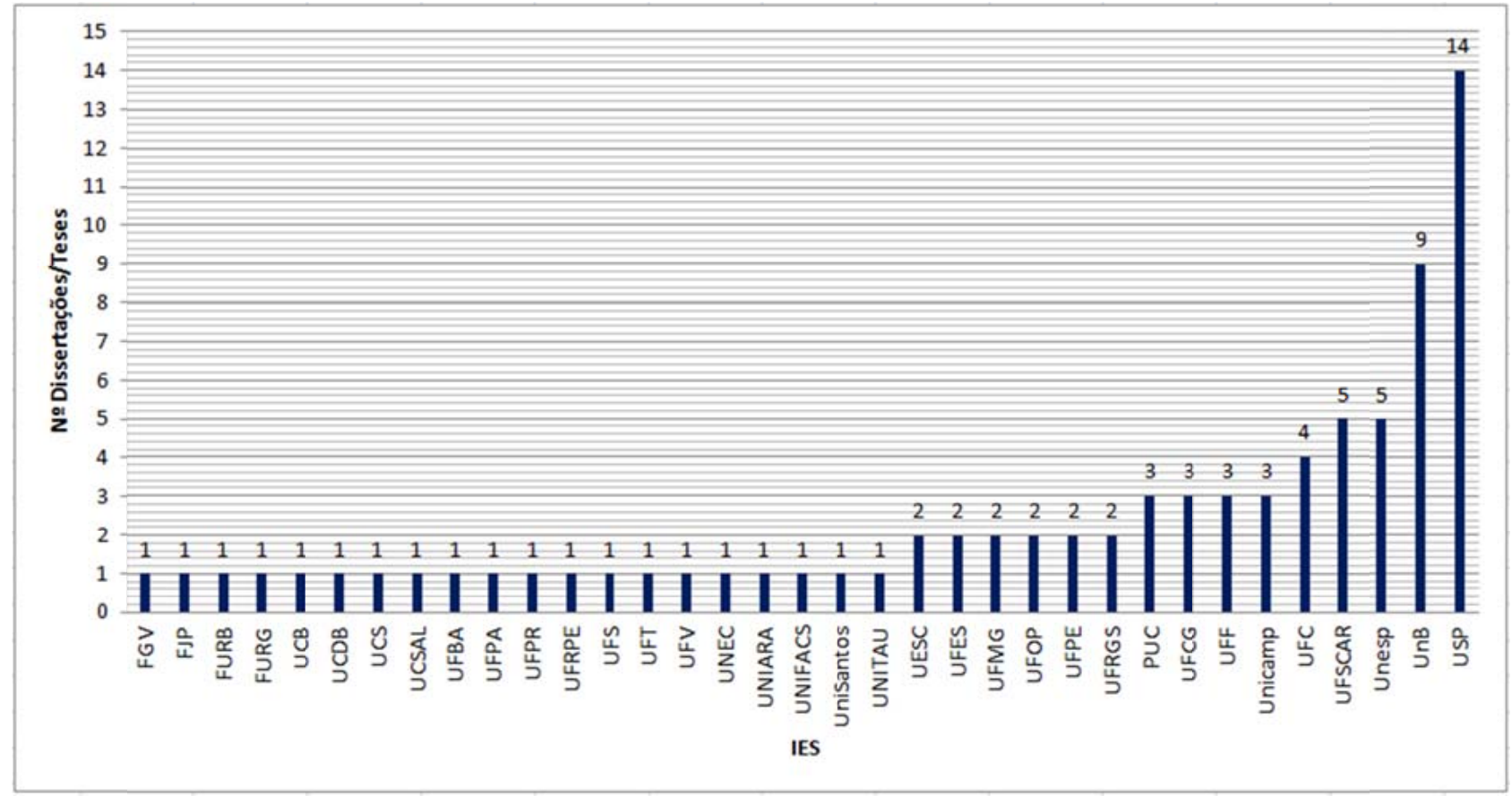

Fonte: Dados compilados pelo autor a partir de informações do Banco de Dados Capes (1987 a 2012)

Observa-se que o assunto mostra-se como um terreno extremamente fértil para o desenvolvimento de estudos e, nessa perspectiva destaca-se a USP, com dois grupos de pesquisa voltados à análise das ações dos Comitês no Estado de São Paulo: o do Programa de Pós-Graduação em Ciência Ambiental (PROCAM) da Universidade de São Paulo (USP), no qual se destaca a produção de inúmeros artigos, dissertações e teses, e o segundo grande grupo que desenvolve suas pesquisas na Faculdade de Arquitetura e Urbanismo da Universidade de São Paulo (FAUUSP), sob a orientação do Prof. Dr. José Luiz Caruso Ronca. Nos últimos anos, esse grupo produziu dezenas de artigos científicos, capítulos de livros, dissertação de mestrado e teses de doutorado (ALVIM, 2003).

Neste universo de pesquisa destaca-se também a atuação da Universidade de Brasília (UnB) que juntamente com a USP e outras IES nacionais e internacionais (Universidade Federal da Bahia, Universidade Estadual do Rio de Janeiro, Universidade Regional de Blumenau, Universidade Johns Hopkins (JHU) e Universidade de Michigan (UMICH) - EUA) integraram o Projeto Marca D'Água, cujo objetivo era analisar, de forma comparativa, o processo de organização de organismos de bacia, 
com ênfase nos condicionantes políticos, econômicos e sociais do processo e sua relação com o modelo de gestão implementado. Observa-se neste projeto, a produção de 3 Cadernos intitulados: Retratos 3 x 4 das bacias pesquisadas (2003); Comitês de bacia sob o olhar dos seus membros (2008) e Água e Política. Atores, Instituições e Poder nos Organismos Colegiados de Bacia Hidrográfica no Brasil (2010).

Entretanto, é importante ressaltar, a preocupação das IES de todas as regiões do país, com estudos voltados aos Comitês de Bacia Hidrográfica e, por consequência, à gestão integrada dos recursos hídricos. Nota-se, porém, apenas 1 trabalho (dissertação) proveniente da Região Norte, pelo fato de que os estados que compõem essa região foram os últimos a estabelecerem uma estruturação político-institucional de gestão das águas.

A Região Norte, maior detentora de água, com cerca de 70\% dos recursos hídricos do país e 7\% da população, possui instalado apenas 4 Comitês de Bacia Hidrográfica (sendo 1 no Estado do Amazonas e 3 no Estado de Tocantins) (LOPES \& TEIXEIRA, 2012).

A análise do foco de estudo dos trabalhos é bastante diversificada, observando-se que a maioria aborda a atuação de um Comitê de Bacia Hidrográfica especifico, entretanto, outros trabalhos realizam uma abordagem geral dos Comitês. Alguns trabalhos analisam especificamente Subcomitês, estâncias menores dentro do arranjo institucional, outros ainda estabelecem comparações entre dois ou mais Comitês. Apesar dessa grande variedade, destacam-se trabalhos voltados ao CBH-Alto-Tietê e outros do Estado de São Paulo (CBH Tietê-Jacaré; CBH Piracicaba, Capivari e Jundiaí; CBH Mogi).

Essa tendência se deve por ser o Estado de São Paulo um dos principais protagonistas na criação do sistema integrado e na implantação dos instrumentos de Gestão dos Recursos Hídricos, especialmente com a criação do Fundo Estadual de Recursos Hídricos - FEHIDRO, instância de apoio econômicofinanceiro da Política Estadual de Recursos Hídricos, de acordo com a Lei Estadual 7663/91.

De modo geral, essa miscelânea contribui para ampliar a base de dados e discussões sobre o tema, formando um painel sobre o assunto no Estado de São Paulo e no Brasil.

Os trabalhos por sua vez foram separados em grandes áreas, de acordo com os Programas de Mestrado/ Doutorado: Ciências Exatas e da Terra; Ciências Biológicas; Engenharias; Ciências da Saúde; Ciências Agrárias; Ciências Sociais Aplicadas; Ciências Humanas; Linguística, Letras e Artes; e Multidisciplinar. Essa classificação das Áreas do Conhecimento, estabelecida pela CAPES, tem finalidade eminentemente prática, objetivando proporcionar uma maneira ágil e funcional de agregar as informações, em virtude da afinidade de seus objetos, métodos cognitivos e recursos instrumentais, refletindo contextos sociopolíticos específicos.

Essa hierarquização apresenta quatro níveis, que vão do mais geral aos mais específicos, abrangendo 9 grandes áreas, 79 áreas e 344 subáreas do conhecimento, justificando a escolha da divisão dos trabalhos na área de maior abrangência.

A análise evidenciou a existência de trabalhos em 7 grandes áreas, inexistindo trabalhos em Ciências Biológicas e Linguística, Letras e Artes. Destaca-se que grande parte dos trabalhos é proveniente da grande área Multidisciplinar com 26 Dissertações e 5 Teses, totalizando 38\% dos trabalhos, sendo seguido de Ciências Humanas com 22 Dissertações e 5 Teses, totalizando 33\%; 8 Dissertações e 3 Teses (14\%) na grande área Ciências Sociais Aplicadas; 6 Dissertações e 1 Tese (9\%) - Engenharias; 1 Dissertação e 1 Tese $(2,5 \%)$ para cada uma das grandes áreas Ciências da Saúde e Ciências Exatas e da Terra, e por fim 1 (1\%) trabalho (Dissertação) voltado para Ciências Agrárias (Figura 3). 
Figura 3 - Gráfico crescente representando a quantidade e o percentual de teses segundo a área determinada pela CAPES

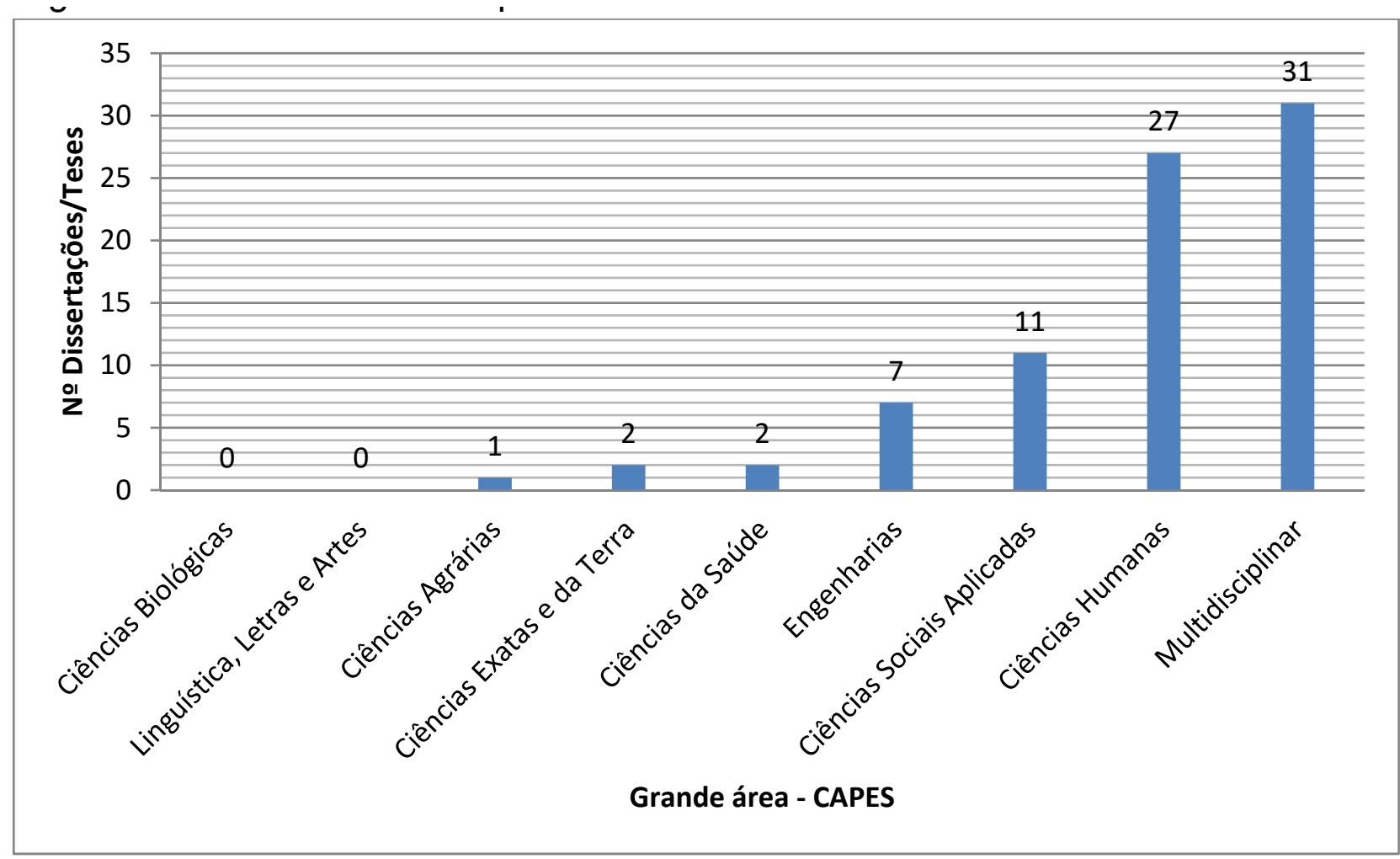

Fonte: Dados compilados pelo autor a partir de informações do Banco de Dados Capes (1987 a 2012)

Segundo informações disponíveis no portal eletrônico da CAPES (www.capes.gov.br), entre as grandes áreas de Pós-Graduação Stricto Sensu, as multidisciplinares foram as que mais cresceram entre $2004 \mathrm{e}$ 2009, passando de 152 para 382, um avanço de $151 \%$.

Deponti (2007) destaca que a multidisciplinaridade é o tratamento de uma temática comum por diferentes disciplinas que, embora percebidas de forma individual (disciplinar), fornecem uma síntese, havendo uma cooperação sistemática entre elas e permitindo a compreensão mais real e global do objeto analisado.

Desse modo, a análise do Comitê de Bacia Hidrográfica poderá ser cumprida mais eficazmente, quando realizada de maneira interdisciplinar por meio do diálogo com as diferentes áreas de conhecimento.

Independente da área é importante ressaltar que essa troca de experiências entre pares de variadas origens e situações, que lidam com problemáticas a partir de enfoques diferentes, pode ser enriquecedor para o aprendizado e entendimento das dinâmicas que envolvem os Comitês.

\section{Análise Temática}

Em relação as palavras-chave, é importante ressaltar que esse levantamento apresentou divergências ou falta de informações comparando-se o portal da CAPES e os trabalhos na integra. Em alguns casos, o Banco de Teses e Dissertações (CAPES) não trazia as palavras-chave ou apresentava uma quantidade inferior a descrita nos trabalhos científicos. Esse problema expressa a necessidade de maior cuidado na inserção de informações por parte das IES no referido portal.

O Cadastro de Discentes, no portal da CAPES, tem por objetivo armazenar e manter atualizados, através 
de aplicativo próprio, todos os dados relativos à comunidade dos alunos de mestrado e doutorado, desde a matrícula até a titulação. Desse modo, essas informações tornar-se o instrumento formal de registro do envio das teses e dissertações para o Banco de Teses da CAPES, disponibilizado no site "Domínio Público", no portal do MEC.

Diante do impasse, optou-se por utilizar as palavras-chave citadas nos trabalhos científicos (Dissertações e Teses) quando disponíveis na Biblioteca Digital das IES ou do próprio site "Domínio Público".

Foram cadastradas 163 diferentes palavras-chave, citadas nas dissertações/teses estudadas. A palavrachave mais utilizada pelos autores foi Comitê de Bacia Hidrográfica, referida 35 vezes, seguida de Recursos Hídricos com 29 vezes, Bacia Hidrográfica com 17 aparições, Gestão de Recursos Hídricos com 14, Participação com 10 citações nos trabalhos, Gestão foi citada 6 vezes e Desenvolvimento Sustentável, Comitês de Bacia e Políticas Públicas tiveram 5 citações cada. As demais palavras estão relacionadas a temas como gestão (Gestão integrada, Gestão Participativa, Gestão Hídrica, etc.), meio ambiente (hidrografia, saúde ambiental, proteção ambiental, percepção ambiental, etc.), legislação (Política ambiental, Política de Recursos Hídricos, Direito Ambiental, etc.), território (Regiões Metropolitanas, UGRHI, etc.) entre outras.

A Norma NBR 6028:2003 da Associação Brasileira de Normas Técnicas (ABNT) define que palavras-chave são palavras representativas do conteúdo do documento, escolhida, preferentemente, em vocabulário controlado, entretanto, observou-se que alguns dos trabalhos analisados não atentaram para tal normatização, visto que as palavras-chave não representavam o conteúdo das Dissertações/Teses.

\section{Análise dos Autores}

A análise dos currículos aponta que os autores se graduaram entre 1974 e 2009; dos 81 trabalhos analisados, 49 foram redigidos por mulheres (61\%) e 31 (39\%), por homens. É importante destacar a participação de um pesquisador com dois Mestrados (um profissional e outro acadêmico), sendo que nesta contagem foi caracterizado como uma única pessoa.

Observa-se que a maior parte dos pesquisadores (40\%) se graduaram entre os anos 2000 a 2009 , seguidos daqueles que concluíram nos anos $90-25$ (32\%), nos anos $80-17$ (3\%), e 4 entre 1974 a 1979 (5\%) em 1968. Ressalta-se que, da amostragem total de 80 pesquisadores, 3 currículos não estavam disponíveis no Lattes; portanto, 77 foram analisados.

Quanto ao curso de formação (graduação), os resultados encontrados indicam uma grande variedade de cursos, destacando-se a Geografia, com 13 profissionais (17\%); seguido de Direito, com 10 formados (13\%); Ciências Sociais com 8 (10\%); Ciências Biológicas e Administração, com 5 formados (6\%) cada; Engenharia Civil e Arquitetura e Urbanismo com 4; Engenharia Química, Jornalismo e Ciências Econômica com 3; Engenharia Agronômica, Engenharia Ambiental, Agronomia, Ciência Política e Enfermagem com 2, e, finalizando, vêm os cursos de Gestão Ambiental, Ciências da Computação, Química Industrial, Economia, Serviço Social, Turismo, Comércio Exterior, Administração Pública, Engenharia Sanitária e Ambiental e Engenharia de Recursos Hídricos com 1 (um) para cada área (Figura 4). 
Figura 4 - Gráfico crescente representando a quantidade e o percentual de autores e seus cursos de graduação, segundo análise dos currículos disponíveis na Plataforma Lattes

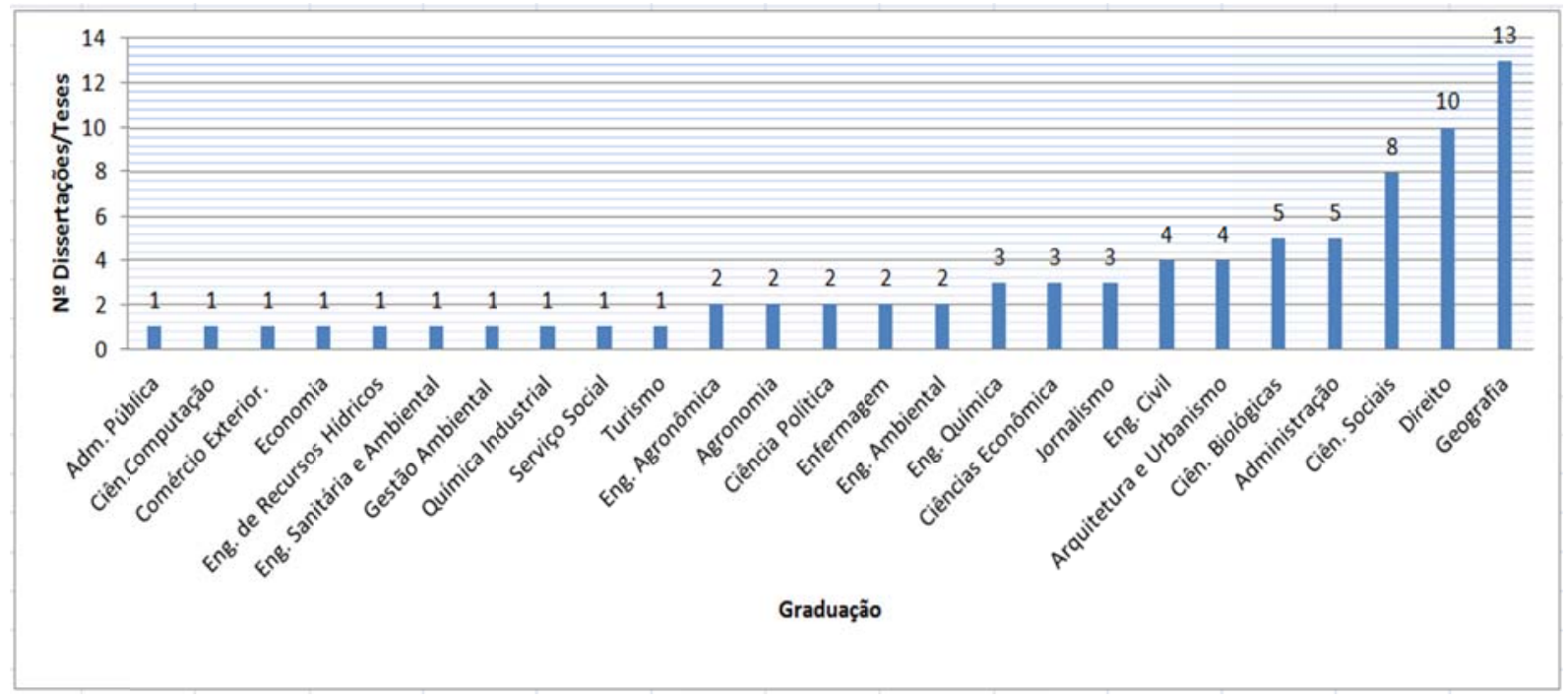

Fonte: Dados compilados pelo autor a partir de informações do Banco de Dados Capes (1987 a 2012)

No geral, os pesquisadores vieram de distintas áreas de formação na graduação, refletindo na grande diversidade de áreas do conhecimento em que estão inseridas as dissertações/teses.

$\mathrm{O}$ conhecimento dessa dinâmica $(\mathrm{CBH})$ passa por complexos conhecimentos de diversas áreas. Conhecimentos que demandaram, ao longo do tempo, a formação de extensas redes profissionais para se montar uma estrutura o entendimento dos diversos mecanismos que atuam sobre o novo arranjo institucional definido pela Política Nacional de Recursos Hídricos.

\section{Análise dos procedimentos metodológicos}

Buscou-se nesse item relatar as principais ferramentas metodológicas utilizadas pelos autores para alcançar seus objetivos. Entretanto, há de se destacar o desafio de conceber tal análise, pois, apesar das normas definidas pela Associação Brasileira de Normas Técnicas - ABNT utilizadas pelos programas e do processo minucioso de construção das etapas que regem um trabalho científico, observou-se uma grande diversidade na forma de redigir e estruturar os textos.

Por exemplo, em alguns casos, o autor optou por redigir e organizar seu texto em capítulos, como um livro; assim, cada capítulo tem um ou mais objetivos que, por sua vez, trazem seus respectivos procedimentos metodológicos. Essa forma de redação tem como objetivo facilitar a publicação durante o curso, pois cada capítulo da pesquisa resulta em um artigo.

Para realização dessa etapa optou-se pela leitura inicial dos Resumos. Medeiros (2000) define resumo como "[...] um tipo de redação informativo-referencial que se ocupa de reduzir um texto a suas ideias principais" (p. 107). Menciona ainda que "para o pesquisador, o resumo é um instrumento de trabalho [...]" e que constitui numa "[...] apresentação sintética e seletiva das ideias de um texto, ressaltando a progressão e articulação delas" (p. 123).

É importante destacar que muitas vezes, a análise do resumo foi insuficiente para entendimento e delimitação dos procedimentos metodológicos utilizados nas Dissertações e Teses, sendo necessária a pesquisa da obra completa, o que algumas vezes não estava disponível. Desse modo, essa parte da 
pesquisa apresenta uma visão geral dos principais instrumentos de pesquisa, não sendo aconselhável a apresentação de dados quantitativos.

Observa-se ainda a inexistência, nos trabalhos acadêmicos, de um tópico, capítulo ou subcapítulo voltado especificamente aos Procedimentos Metodológicos utilizados na pesquisa, sendo muitas vezes, incorporado na Introdução.

Entretanto, apesar de tais dificuldades encontradas, observa-se que a maior parte utilizou uma ou mais das seguintes técnicas: entrevista, questionário, observação local, pesquisa-ação, análise da realidade empírica e observação livre e participante.

O estudo de caso, como ferramenta metodológica, esteve presente em alguns trabalhos, visto se tratar de um objeto especifico de pesquisa, o Comitê de Bacia Hidrográfica.

$\mathrm{Na}$ visão dos autores, nestes tipos de trabalho acadêmico (Dissertação e Tese) recomenda-se a necessidade da utilização do resumo informativo que, conforme Norma NBR 6028:2003 da ABNT, tem por finalidade informar ao leitor os objetivos, metodologia, resultados e conclusões do documento, de tal forma que este possa, inclusive, dispensar a consulta ao original.

Outro ponto a ressaltar, é a necessidade do zelo com a linguagem escrita, considerada um requisito imprescindível a todo e qualquer texto, sobretudo o acadêmico, o qual, consensualmente, requer muito cuidado e atenção independente da área do conhecimento.

\section{CONSIDERAÇÕES FINAIS}

Os resultados, aqui apresentados, expressam o amadurecimento de uma área de pesquisa, porém assinala algumas lacunas temáticas que precisam ser preenchidas.

Os diversos trabalhos produzidos podem e devem servir como subsídios para reflexão e prática daqueles que atuam diretamente nos Comitês de Bacia Hidrográfica, seja para construção de um instrumento de gestão eficiente e sustentável, ou para aprimoramento das ações e projetos desenvolvidos nessas instâncias participativa e democrática, conhecidas como "parlamento das águas".

O gerenciamento de bacias hidrográficas, a partir das bases acadêmicas, deve ser estimulado com programa de formação em recursos humanos no nível de mestrado (acadêmico e profissionalizante), doutorado e especialização, produzindo pesquisadores e gestores com uma visão sistema e integrada, além de resultados que possam auxiliar na gestão dos recursos hídricos por parte dos Comitês de Bacia Hidrográfica.

Por fim, outros trabalhos como este poderão e deverão ser elaboradas, nas mais diversas áreas e temáticas, para que movidos pelo desafio de conhecer o já construído e produzido, se possa buscar o que ainda não foi realizado.

\section{REFERÊNCIAS}

ABERS, R.; JORGE, K. D. Descentralização da gestão da água: por que os comitês de bacia estão sendo criados? Revista Ambiente e Sociedade, Campinas, v. 8, n. 2, p. 99-124, jul./dez. 2005.

ABNT - Associação Brasileira de Normas Técnicas. NBR 6028:2003. Nov. 2003. Disponível em: http:// www.ufrgs.br/termisul/oa3/Norma_ABNT.pdf. Acesso em: 22 jul. 2013.

ALVIM, A. A. T. B. A contribuição do comitê do Alto Tietê à gestão da bacia metropolitana, 19942001. São Paulo, 2003. Tese (Doutorado em Arquitetura e Urbanismo) - Faculdade de Arquitetura e Urbanismo, Universidade de São Paulo. 
BRASIL. Lei Federal no 9.433, de 08 de janeiro de 1997. Institui a Política Nacional de Recursos Hídricos. Disponível: em: <http://www.sigrh.sp.gov.br/sigrh/basecon/lrh2000/LF/Leis/Lei9_433.htm>. Acesso em: 20 jul. 2013.

DEPONTI, C. M. A multidisciplinaridade no enfrentamento das questões ambientais e a economia ecológica. In: CONGRESSO DA SOCIEDADE BRASILEIRA DE ECONOMIA, ADMINISTRAÇÃO E SOCIOLOGIA RURAL, 65 2007, Londrina. Anais... CD ROM XLV Congresso da Sociedade Brasileira de Economia, Administração e Sociologia Rural, 2007.

FRACALANZA, H; LIMA, I. A educação ambiental no Brasil: análise da produção acadêmica. Campinas: Unicamp, 2006.

GARJULli, R. Os recursos hídricos no semiárido. Ciência e Cultura, São Paulo, v. 55, n. 4, p. 38-39, 2003.

KETTELHUT, J. T. S.; AMORE, L.; LEEUWESTEIN, J. M. A experiência brasileira de implementação de comitês de bacias hidrográficas. In: SIMPÓSIO INTERNACIONAL SOBRE GESTÃO DE RECURSOS HÍDRICOS, 1998, Gramado. Anais... Gramado: ABRH, 1998.

LOPES, M. M.; TEIXEIRA, D. A trajetória da Gestão dos Recursos Hídricos no Brasil: panorama geral dos estados brasileiros. In: CONGRESSO NACIONAL DE EXCELÊNCIA EM GESTÃO, 8, 2012 , Rio de Janeiro. Anais.... . Rio de Janeiro: LATEC/UFF, 2012. v. 8

MASCARENHAS, A. C. Comitê de bacia hidrográfica: o que é, como funciona, e que papel desempenha na gestão dos recursos hídricos. In: Plenarium, v.3, n. 3. Brasília: Câmara dos Deputados, Coordenação de Publicações, 2006.

MEDEIROS, J. B. Redação científica: a prática de fichamentos, resumos, resenhas. 4. ed. São Paulo: Atlas, 2000.

ROMANOWSKI, J.; ENS, R. As pesquisas denominadas do tipo "Estado da Arte” em Educação. Diálogo Educacional, v.6, p.37-50, set./dez. 2006.

SOARES, G. A. D. O Portal de Periódicos da Capes: dados e pensamentos. Revista Brasileira de PósGraduação, v. 1, n. 1, p. 10-25, 2004.

SOARES, M. Alfabetização no Brasil:O Estado do conhecimento. Brasília: INEP/MEC, 1989.

TEODORO, V. L. I.; TEIXEIRA, D.; COSTA, D. J. L.; FULLER, B. B. O conceito de bacia hidrográfica e a importância da caracterização morfométrica para o entendimento da dinâmica ambiental local. Revista UNIARA, Araraquara, v. 20, p. 137-156. 2007.

TUNDISI, J. G. A Formação de Recursos Humanos em Recursos Hídricos no Brasil: Estratégias e Perspectivas de Avanço. In: BRASIL. Plano Nacional de Pós-Graduação - PNPG 2011-2020. Brasília: CAPES, 2010. v.2. p. 81-94. 
VASCO, A. P.; ZAKRZEVSKI, B. B. O estado da arte nas pesquisas sobre percepção ambiental no Brasil.

Perspectiva, Erechim, v. 34, n. 125, p. 17-28, mar. 2010. 